TAPROBANICA, ISSN 1800-427X. June, 2014. Vol. 06, No. 01: pp. 47-48.

(C) Research Center for Climate Change, University of Indonesia, Depok, Indonesia \& Taprobanica Private Limited, Homagama, Sri Lanka http://www.sljol.info/index.php/tapro

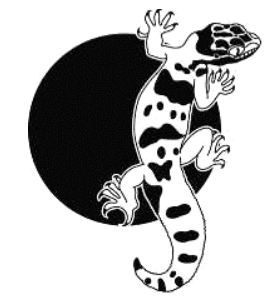

\section{A pentastome (Armillifer moniliformis) parasitizing a common rat-snake}

Pentastomes are a group of relatively poorly known parasites that are neglected both in veterinary parasitology text books and curriculum (Jean, 2008). The pentastomes are currently classified in a separate phylum, Pentastomida, because they exhibit characteristics of both the phylum Arthropoda and Annelid. This group comprises of approximately 100 species of vermiform arthropods that are all obligate parasites of the lower and less often upper respiratory tract of vertebrates (Riley, 1986). Adult pentastomes are segmented and worm like, measuring 0.5 to $20 \mathrm{~cm}$ in length (Lavrou et al., 2004). However they are easily distinguished from any other parasite because they bear 2 pairs of retractile hooks on either side of the mouth (Jean, 2008). They also have a distinct tongue shaped appearance; hence they are called linguatulids or tongue worms (Lavrou et al., 2004).

Reptiles act as definitive hosts for many pentastomes species (Self, 1969). Five genera contain the most common pentastomids encountered in reptiles; Raillietiella, Armillifer, Porocephalus, Sebekia, and Kiricephalus. Additionally there are 12 other genera known to use reptilian hosts (Drabick, 1987). They have been found in snakes adapted to different habitats; terrestrial, aquatic, semi-aquatic reptiles, and arboreal tree snakes (Drabick, 1987). Raillietiella is the largest genus of pentastome, while Armillifer is the most common genus identified from Pythonids and Viperids, Kiricephalus from Colubrids and Porocephalus from Boids and Crotalids (Drabick, 1987).

We found a dead adult male common rat snake (Ptyas mucosus), a Colubrids snake in the Faculty of Science of University of Colombo, Sri Lanka on $25^{\text {th }}$ of February 2010. No external damage was observed. The total length of this snake was $1.18 \mathrm{~m}$ and body weight 3.2 $\mathrm{kg}$. A necropsy of the specimen was performed. Surfaces of internal organs were thoroughly observed for different parasite stages such as adults and cysts. The internal organs liver, lungs, kidney, reproductive organs, and the gastrointestinal track were dissected and observed for parasites under the dissecting microscope. A dark reddish patch was seen on the interior wall of the left lung, $3 \mathrm{~cm}$ from its anterior end. When an incision was made on the reddish patch, a whitish worm like parasite emerged. The specimen was fixed and preserved in $70 \%$ alcohol. The parasite was identified using the taxonomic key by Riley \& Self (1979).

This whitish worm had a characteristic shape and a segmented body. It was $48 \mathrm{~mm}$ long with 50 body rings. The diameter of the cephalothorax was wider than the abdominal diameter (Fig. 1). Four external hooks were present in the cephalic region (Fig. 2). We concluded that the parasite was Armillifer moniliformis. This is a novel species and a host-parasitic interaction record in Sri Lanka.

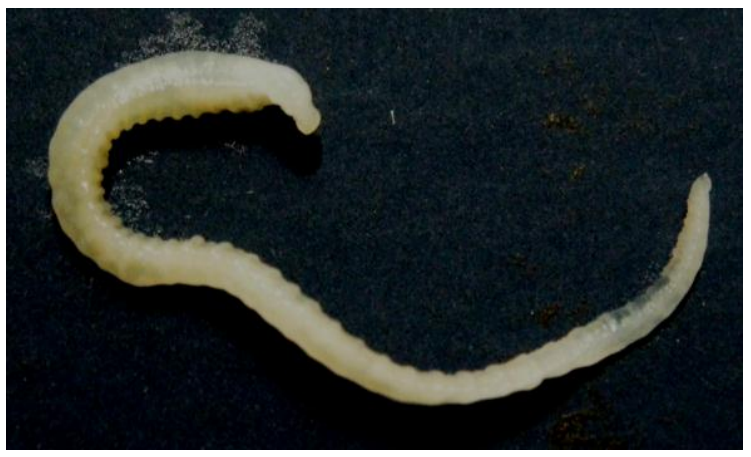

Figure 1: Fresh Armillifer moniliformis

It is important to note that pentastome parasites of reptiles do carry zoonotic potential, although such potential has only been clearly demonstrated for the genera Armillifer and more recently for Porocephalus (Drabick, 1987). The life cycle of Armillifer species is believed to alternate between a snake-mouse 
cycle and one involving snakes and other mammals. Most Armillifer species infections are acquired when under cooked snake meat is consumed, but may also involve ingestion of water contaminated with snake feces. The major pathology induced by these parasites is tissue damage at the site of their attachment to the host. Inflammation and cellular responses vary with the number of parasites, location and severity of the tissue penetration. Rat snake is a commonly occurring reptile in anthropogenic habitats. Therefore it is very important to study the zoonotic potential of this parasite in Sri Lanka.

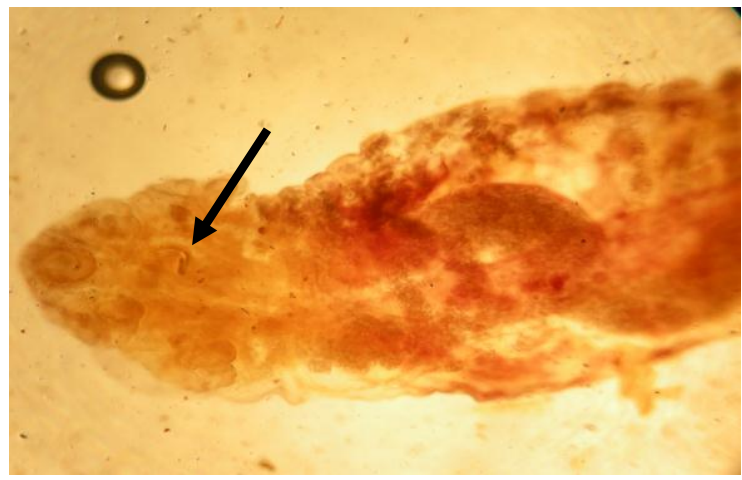

Figure 2: Armillifer moniliformis cephalothorax region cleared with clove oil $(\times 10 \times 20)$. One of the four external hooks in the cephalic region is visible here (arrow).

\section{Acknowledgements}

We are thankful to the Department of Zoology, Faculty of Science, University of Colombo, Sri Lanka for providing the facilities for the dissection.

\section{Literature cited}

Drabick, J. J., 1987. Pentastomiasis. Review of Infectious Diseases, 9: 1087-1094.

Jean, A. P., 2008. An overview of Pentastomiasis in reptiles and other vertebrates. Journal of Exotic Pet Medicine, 17: 285-294.

Lavrou, D. V., W. M. Brown, and J. L. Boore, 2004. Phylogenetic position of the pentastomide and (pan) crustacean relationships. Proceedings of the Royal Society of London, Biological Science, 271: 537-544.

Riley J., 1986. The biology of pentastomids. Advance Parasitology, 25: 45-128.
Riley, J. and J. T. Self, 1979. On the systematic of the pentastomoid genus Porocephalus (Humboldt, 1811) with descriptions of new species. Systematic Parasitology, 1: 25-42.

Self, J.T., 1969. Biological relationships of the Pentastomide: a biobliography on the Pentastomida, Experimental Parasitology, 24: 63-119.

Submitted: 31 Jan. 2014, Accepted: 23 April 2014 Section Editor: Colin Chapman

\section{T. S. P. Fernando ${ }^{1}$ \& V. A. K. Fernando ${ }^{2}$ \\ ${ }^{1}$ Department of Zoology, Faculty of Natural Sciences, The Open University of Sri Lanka, Nawala, Nugegoda, Sri Lanka E-mail: saminda@ou.ac.lk \\ ${ }^{2}$ Department of Zoology, Faculty of Science, University of Colombo, Colombo 03, Sri Lanka E-mail:vink1025@gmail.com}

